Abstracta Iranica Abstracta Iranica

Revue bibliographique pour le domaine irano-aryen

Volume 25 | 2004

Comptes rendus des publications de 2002

«'The Akhalgori Hoard'. An attempt at Dating and Historical Interpretation ». AMI 33, (2001), pp. 143-190.

Aurélie Daems

(2) OpenEdition

Journals

Édition électronique

URL : http://journals.openedition.org/abstractairanica/4277

DOI : 10.4000/abstractairanica.4277

ISSN : 1961-960X

Éditeur :

CNRS (UMR 7528 Mondes iraniens et indiens), Éditions de l'IFRI

Édition imprimée

Date de publication : 15 mai 2004

ISSN : 0240-8910

Référence électronique

Aurélie Daems, « «'The Akhalgori Hoard'. An attempt at Dating and Historical Interpretation ». AMI 33, (2001), pp. 143-190. », Abstracta Iranica [En ligne], Volume 25 | 2004, document 69, mis en ligne le 15 mars 2006, consulté le 25 septembre 2020. URL : http://journals.openedition.org/abstractairanica/ 4277 ; DOI : https://doi.org/10.4000/abstractairanica.4277

Ce document a été généré automatiquement le 25 septembre 2020.

Tous droits réservés 


\section{"'The Akhalgori Hoard'. An attempt at Dating and Historical Interpretation ». AMI 33, (2001), pp. 143-190.}

\section{Aurélie Daems}

L'A. propose une nouvelle datation du trésor d'Akhalgori, initialement daté entre les $6^{\mathrm{e}}-4^{\mathrm{e}} \mathrm{s}$. av. J.-C. et considéré comme appartenant à la culture achéménide locale. Compte tenu des objets retrouvés - boucles d'oreilles, mors de chevaux, phialai en argent - l'A. suggère qu'il s'agirait plutôt du mobilier de la tombe d'une femme, enterrée à l'époque post-achéménide, au tournant $d u 4^{\mathrm{e}}-3^{\mathrm{e}} \mathrm{s}$. Se fondant sur le contenu d'autres tombes fouillées dans la région et sur plusieurs objets précieux provenants de l'intérieur de l'empire achéménide, il déduit qu'une partie des objets sont de l'époque achéménide, tandis que le reste serait post-achéménide. Il suggère que la femme faisait partie de l'entourage d'un satrape ayant fui l'empire après sa chute, emportant des obj ets de famille, ce qui expliquerait les dates différentes. Cet article est important car, pour la première fois, le trésor d'Akhalgori est étudié par rapport à des objets provenant de fouilles scientifiques.

\section{INDEX}

Thèmes : 3.2.2. Pré-Achéménides et Achéménides 


\section{AUTEURS}

AURÉLIE DAEMS

Paris 